\title{
14
}

\section{A Melanesian view of archaeology in Vanuatu}

\author{
Edson Willie
}

Archaeology in Vanuatu is generally considered a 'no go' field of study, as it ventures into areas which a typical ni-Vanuatu is taught at a very early age are restricted and forbidden to members of the community. A lot of archaeological areas of study such as human remains, old or abandoned villages, and sacred and spiritual sites are areas that are associated with spirits of our ancestors; disturbing these areas, or even entering the compound, could lead to unforeseen disease or the death of a relative as a warning - or even your own death. A recent archaeological survey carried out on Nalolo Bay, east Maewo (Sand et al. 2016), saw a cancellation of a visit to a sacred site as the local guides were fearful that something might happen, especially to the locals, as they knew the area was tabu. Venturing into the area might be seen by the spirits as an act of war and they would retaliate and punish us, but more of the punishment would befall the locals as they knew the place was tabu and still went.

Consequently, it is quite difficult to begin working as an archaeologist when growing up in a traditional cultural environment. However, through education and training, one can progressively understand the scope and aims of archaeology and end up comprehending the reasoning behind having to venture into such forbidden areas. As a result, being an archaeologist and a ni-Vanuatu has allowed me to attune the custom beliefs and practices of local communities with archaeological practices. Seeing the two sides of the same coin brings a sense of security and peace to the community, which then becomes a fertile ground for harmonious working relationships with archaeologists. This in turn motivates the parties involved to adhere to sound work ethics, leading to a much safer and respectful working environment.

\section{Kastom in Vanuatu}

Vanuatu is a small island nation that is deeply rooted in cultural traditions and beliefs. Daily lives of communities revolve around sacred rituals and kastom ceremonies that guide the activities that occur within local communities. Each individual, whether male or female, has a traditional obligation to ensure the continuation of custom and culture within societies. Such obligations include activities that are associated with different gender and age groups: young boys' initiation into manhood, ranking systems and girls' initiation into womanhood, up to the time a person dies.

The traditional practices that have been going on for over hundreds of years and over a lot of generations were not completely suppressed by the missionaries. Whilst some customs were modified by them-for example, on Futuna Island the planting of kava was considered by Christianity as forbidden and was abandoned—in most areas, such as south Vanuatu, Christianity 
was integrated into the local religious practices. For example, Christianity was widely accepted into communities after missionaries who were given sacred/taboo lands to settle did not get sick or die, proving their belief in a much stronger deity (Flexner 2016).

All in all, custom beliefs, practices and values are very important in Vanuatu. At first glance, this emphasis on tradition can pose an opposition to archaeological work. Being an archaeologist and a ni-Vanuatu has allowed me to identify the cultural aspects of local communities that can clash with archaeology when the objectives are not properly explained.

Respect is paramount, especially in Vanuatu where cultural beliefs, as mentioned before, are quite dominant. Respect is instilled into the young at a very early age by the elders. They are taught about the importance of traditions and customary laws, and a sense of responsibility is inculcated in them as they grow up and get involved in activities such as gardening, hunting or getting married. Because archaeologists often have to venture into, some would say disturb, culturally restricted areas in order to understand the past, they can appear in opposition to certain traditions and in consequence the field of archaeology can be frowned upon by the local population. In some cases, people can be afraid that their oral traditions related to migration or origins of clans or tribes could be discredited or contradicted by archaeological work.

Another classic example is the work done by archaeologists on human remains, which are usually associated with spirits and avoided altogether. 'Bone diggers' is the name given to the field of archaeology by the indigenous population as the field is relatively new and archaeologists are associated with human remains. The fear of disturbing human remains is something that is instilled at a very early age by customary stories that are told around the fire by elders and peers. Human remains are considered sacred, and it is said that disturbing them can lead to unforeseen illnesses that could also lead to death. This has caused limitations and restriction for archaeological research in certain areas where skeletal remains are quite taboo and are feared and/ or revered. In 2013, archaeological excavations on a mission site (Watt mission) on Kwamera, south Tanna, revealed skeletal remains beneath the foundation of the mission house. Further excavation of the burial to expose the skeletal remains was done in 2014 (Flexner and Willie 2015). A lot of curious bystanders came to witness as the remains were slowly being uncovered, a majority of whom were wary but soon became interested as the dig slowly began to uncover the rest of the remains. Although they were interested, they still maintained their beliefs and ordered that the remains were not to remain uncovered overnight for fear of upsetting the spirits which would result in illness, even death.

\section{Indigenous perspective}

Overcoming one's cultural beliefs and fears is a major achievement for a local archaeologist. Archaeologists who grow up with traditional customs and beliefs benefit from having a privileged perspective, as they grasp both archaeological and traditional aspects of a situation. Archaeology allows one who can relate to these restrictions to actually see and understand the benefits of carrying out research into sacred aspects of culture, and how research can be transmitted back to the communities concerned in layman's terms for them to also understand and appreciate the research that is taking place. By identifying these beliefs and traditions, one is able to see that archaeology does not interfere with customs and oral histories but rather that its findings often allows for their stories to be confirmed or extended further back in time, often to a period earlier than oral traditions. 
In 2016, an archaeological survey was carried out on Maewo Island. The project was a collaboration between the Vanuatu Cultural Centre (VCC) and the Institute of Archaeology of New Caledonia and the Pacific (Sand et al. 2016). Maewo Island, as with most island communities in Vanuatu, holds very strong beliefs in their customs, traditions and oral histories. The news that a group of people had come to research their history was met with curiosity, even though some were opposed to the idea. The local population was very sceptical of what research was going to be carried out. The team had to define and explain the field of archaeology and also give assurance that sacred areas would not be disturbed and the purpose of the survey was to help them better understand their history and would in no way rewrite their oral traditions.

\section{Fieldwork}

The VCC's network of fieldworkers (commonly referred to as filwokas) has also helped greatly with archaeological research across Vanuatu. They contribute to awareness of the field of archaeology and its significance to the cultural heritage of societies, the island and the country as a whole. Archaeological training, funded by The Australian National University (Bedford et al. 2011; Bolton 1999) from 1997 to 1999 and the Sasakawa Pacific Island Nation Funds (Bedford and Regenvanu 2003) from 2001 to 2003, has also helped greatly in empowering the fllwokas with knowledge, which they take back to their home islands, therefore allowing archaeological research to take place within the communities.

The VCC's filwokas work closely with researchers, the vast majority of whom come from outside of Vanuatu. Filwokas play a key role in communicating what is being done and how it will benefit the community they belong to. The fact that filwokas are part of the communities where research is undertaken facilitates gaining the trust of the community when arguing that the work will not pose any risk or threat to the cultural beliefs and that the research will be greatly beneficial to their cultural heritage.

Archaeologists follow traditional ways of life while on fieldwork in communities, which greatly helps to establish quality working relationships. Employing locals to work on the project is also a practice that has many advantages. Not only do the people hired learn about the significance of archaeology and about the history of their community, they also gain a bit of money in the process. Observing customs and traditions is also part of the working relationship between archaeologists and the communities: these include kastom ceremonies, feasts, funerary rites and marriages, as well as attending church on Saturdays or Sundays. Overall, this creates a pleasant environment which reduces the risk of people opposing archaeological excavations.

The Forestry and Protected Areas Management Project saw a holistic approach taken to conservation. The project considered the biological, social/cultural, economic and environmental aspects of conservation within an area. In dealing with cultural aspects of the area, cultural surveys were the main area of interest and therefore cultural traditions/ceremonies were observed before commencement of work. One of the areas selected for the conservation project was Lake Letas, Gaua Island, which is a lake formed in the crater of an old volcano, forming a semicircle around a current existing one (Mount Garett). A nangarie plant had to be planted at what is believed to be the entrance of the lake to appease the spirit looking after the lake so that this was a friendly visit and was not a threat to the area (Willie 2016). 


\section{Conclusions}

As a local archaeologist who grew up with traditional customs and beliefs, I think the field of archaeology provides an in-depth understanding of the teachings and oral history which has been passed down over generations, which makes archaeological research really fascinating. Archaeology gives reasoning to traditional practices such as the irrigation systems on Aneityum (Spriggs 1981), which were left and used as we see them, and could also be revitalised in the present.

Although archaeology is a relatively new concept to the indigenous population of Vanuatu, recognition of the importance of this field and its contribution to the country's cultural heritage is slowly gaining momentum. The discovery of the Lapita cemetery at Teouma in 2004 and other findings from subsequent research projects have helped to shed light on the origins of the first settlers of Vanuatu and on the Pacific's history in general. Being a ni-Vanuatu archaeologist has helped me flesh out the stories that are told over the fire across the archipelago regarding our origins and our heritage.

\section{References}

Bedford, S and R Regenvanu. 2003. Summary report for the Vanuatu government on distance education in the South West Pacific: Cultural Heritage training 2001-2003: Archaeology training program on Urivpiv and Wala Islands, Malakula, 2001. The Sasakawa Pacific Island Nations Fund.

Bedford, S, M Spriggs, R Regenvanu and S Yona. 2011. 'Olfala histri we i stap andanit long graon. Archaeological training workshops in Vanuatu: A profile, the benefits, spin-offs, and extraordinary discoveries'. In Working together in Vanuatu: Research histories, collaborations, projects and reflections, edited by J Taylor and N Thieberger, 191-213. Canberra: ANU Press. doi.org/10.22459/WTV.10. 2011.22.

Bolton, L (ed.). 1999. Fieldwork, fieldworkers: Developments in Vanuatu research. Sydney. University of Sydney.

Flexner, JL. 2016. An archaeology of early Christianity in Vanuatu: Kastom and religious change on Tanna and Erromango, 1839-1920. Terra Australis 44. Canberra: ANU Press. doi.org/10.22459/ TA44.12.2016.

Flexner, JL and E Willie. 2015. 'Under the mission steps: An 800 year-old human burial from south Tanna, Vanuatu'. Journal of Pacific Archaeology 6 (2):49-55.

Sand, C, J Bolé, E Willie and A Tilly. 2016. Rapport archaeologique sur la mission au Sud-Maevo (Vanuatu). Noumea: Institute of Archaeology of New Caledonia and the Pacific.

Spriggs, M. 1981. 'Vegetable kingdom: Taro irrigation and Pacific prehistory'. Unpublished PhD thesis, The Australian National University, Canberra.

Willie, E. 2016. 'Forestry and Protected Areas Management Project: Cultural survey of Lake Letes, Gaua Island'. Unpublished report. Port Vila: Vanuatu Cultural Centre. 
This text is taken from Archaeologies of Island Melanesia: Current approaches to landscapes, exchange and practice, edited by Mathieu Leclerc and James Flexner, published 2019 by ANU Press, The Australian National University, Canberra, Australia.

doi.org/10.22459/TA51.2019.14 